\title{
Multilevel Comprehensive Evaluation of Stability of High Rockfill Embankment Based on Fuzzy Analytic Hierarchy Process
}

\author{
Yanqing Zhang ${ }^{1,2}$, Hongjun Jing ${ }^{1,2, *}$ and Jun Dai ${ }^{1}$ \\ ${ }^{1}$ College of Architecture and Civil Engineering, Xi'an University of Science and Technology, Xi'an 710054, China \\ ${ }^{2}$ Road Engineering Research Center, Xi'an University of Science and Technology, Xi'an 710054, China
}

Received 23 June 2021; Accepted 30 October 2021

\begin{abstract}
The stability of high rockfill embankment plays an important role in traffic safety and economic development in mountainous areas. However, owing to the complicated internal structure of the high rockfill embankment, coupled with the influence of external factors, it is difficult to judge its stability with conventional methods. In order to quickly determine the stability, according to the actual situation of fillers composition, self-condition and external factors of high rockfill embankment, combined with fuzzy mathematics theory and the principle of analytic hierarchy process, 16 indexes that have an important impact on the stability of high rockfill embankment were classified, and a multilevel stability evaluation model was established. Weight and reliability of each factor index were analysed by using analytic hierarchy process and reliability theory. Finally, a multilevel fuzzy comprehensive evaluation was carried out on an engineering example to verify the rationality of the model. Results demonstrate that the model has strong operability and good applicability for evaluating the stability of rockfill embankment projects. The method is simple and feasible, the conclusion is reliable, and it has certain advantages. The study results can provide a reference for determining the stability of rockfill embankment projects during construction and operation period.
\end{abstract}

Keywords: High Rockfill Embankment, Stability, Reliability, Analytic Hierarchy Process, Fuzzy Synthetic Evaluation

\section{Introduction}

With the continuous construction of mountain highways, high embankment increases each day. Therefore, stability evaluation of high embankment attracts increasing attention. Research on stability of high embankment is an ancient and complicated topic. At present, stability evaluation methods of roadbed mainly include ultimate equilibrium [1,2], numerical [3,4], and uncertainty analyses [5-9].

Ultimate equilibrium analysis is accepted as a practical method to analyze stability of roadbed slopes due to its simple calculation model. However, this analysis requires information about the sliding surface position and shape in advance. Numerical analysis can intuitively disclose stressstrain state of the roadbed and development condition of the plastic zone, but its results are restricted by the constitutive relation of fillers. Given that the roadbed system is a complicated and changing system, influencing factors of roadbed stability are fuzzy and uncertain. Therefore, appropriate uncertainty analysis can effectively handle problems caused by uncertain factors in roadbed stability evaluation. Uncertainty analysis mainly includes fuzzy theoretical evaluation, neural network evaluation, genetic algorithm, and a combination of multiple methods. Fuzzy mathematics theory is continuously developing and has been applied to various fields since its foundation. Applications of fuzzy mathematics to roadbed engineering mainly focus on three aspects, namely, stability judgment of roadbed, optimization of strength parameters of rock and earth mass, and fuzzy random theory combined with reliability. Fuzzy

*E-mail address: : jinghongjun@xust.edu.cn ISSN: 1791-2377 @ 2021 School of Science, IHU. All rights reserved. doi:10.25103/jestr.145.15 mathematics avoids complexity of several problem details and focuses on effects of primary factors. Detailed problems are manifested in the fuzzification of primary factors, which simplifies problem solving and assures consistency with practical situations.

High rockfill embankment has complicated internal characteristics and irregular structural distribution. Multiple disciplines are involved, including engineering geology, rock mechanics, mathematical statistical analysis, and computer technology. Traditional analytic methods encounter difficult overall evaluations on stability of high rock fill embankment and easily result in different outcomes by different operators, which are attributed to the fuzziness caused by neglecting uncertain factors. However, these shortcomings of traditional analytic methods are effectively offset by fuzzy mathematics [10]. As a result, fast and effective stability evaluation of high rockfill embankment based on fuzzy mathematics theory is of important significance to protect the long-term stable operation of high-grade highways in mountainous areas.

On this basis, and with the aim to provide a reasonable method for engineering design and stability assessment, this study carried out a systematic stability evaluation of high rockfill embankment based on fuzzy mathematics theory.

\section{State of the art}

Stability evaluation of high rockfill embankment has been the key concern in engineering and has been discussed worldwide through different methods. Stability of complicated roadbed in special regions has been evaluated on the basis of fuzzy mathematics theory and effective 
methods have been proposed for its investigation. Following previous studies, Marandi et al. [11] proposed a method to calculate the safety coefficient of soft soil embankment through an equivalent area modification approach using the reduction coefficient, and obtained accurate results. Huang et al. [12] evaluated stability of roadbeds and ordered a ranking model of roadbeds in permafrost regions based on uncertain measurement theory. The uncertain measurement model gained consistent results with fuzzy evaluation approach and provided an effective approach to evaluate roadbed stability in permafrost regions. Liu et al. [10] carried out a multi-factor quantitative evaluation using fuzzy mathematics and analytic hierarchy process (AHP) and proposed a fuzzy synthetic evaluation method for stability of high-speed railway roadbed in cold regions. The method is found reasonable and feasible with results in accordance with engineering practices. Ruan et al. [13] introduced entropy weighted method into extension theory and evaluated thermal stability of permafrost roadbed, obtaining relatively reliable results but encountered limitations in selecting evaluation indexes.

Slope stability of highways is also investigated on the basis of fuzzy theory. Park et al. [14] expressed uncertain parameters of rock slopes in fuzzy numbers, analyzed stability of rock slope using fuzzy set theory, and solved fuzzy uncertainty problem caused by uncertain parameters, which achieved good application effects. Azarafza et al. [15] proposed a fuzzy logic decision algorithm based on block theory and determined reliability of discontinuous rock slope under different wedge-shaped and planar slippages. This algorithm needs no extensive quantitative evaluations of stability. Su et al. [16] proposed a stability evaluation index system based on multiple factors by combining characteristics of rock slopes. With references to the fuzzy optimal recognition theory and case reasoning, two different slope stability evaluation methods were established but with certain limitations in determining index weights. Daftaribesheli et al. [17] studies applications of the fuzzy set theory in grading slope rocks and evaluating their stability. Ye et al. [18] investigated reliability of supporting structure to grating flexible slope with anchor rods and proposed a reliability analysis method that considers fuzzy randomness of soil parameters and reliability of slope support structure in fuzzy transition interval. Results show that reliability analysis of reinforced slope that considers slope fuzziness can reflect its practical state better than previous methods.

A comprehensive evaluation of stability of roadbed slope is also carried out by combining fuzzy theory or other theories and enriched methods to investigate roadbed stability. Zhu et al. [19] proposed a method to evaluate stability of roadbed slope under seismic conditions by combining the catastrophe theory and fuzzy mathematics. This approach is superior to traditional fuzzy mathematical methods in terms of prediction accuracy. Sari et al. [20] predicted stability of clay slope along highways through the combination technique of artificial neural network and fuzzy reasoning system. Gao et al. [21] proposed and applied a new method based on black hole algorithm to analyze stability of high embankment slope to an airport in the Loess Plateau Region. The method obtained good calculation effect and efficiency. Moghadami et al. [22] developed a model using fuzzy synthetic analysis that considered various factors and experiences of experts to evaluate the risks of rock slopes. Results were in high accordance with practical engineering observations. Considering randomness and fuzzy factors that influence stability of highway slopes,
Ruan et al. [23] determined weights of indexes using the comprehensive weighting method based on the maximum entropy principle and engineering fuzzy set theory. An improved fuzzy evaluation is also proposed for stability of highway slopes, which was characteristic of small uncertainty and high reliability.

With the aim to address the shortcomings of existing studies, a systematic stability evaluation was carried out on a high rockfill embankment engineering in the secondary highway of the National Highway 316 from Xunyang to Ankang in the Shaanxi Province of China using the fuzzy mathematics theory. This study is expected to provide a reliable method to investigate stability of high rockfill embankment.

The remainder of this study is organized as follows. Section 3 illustrates the fuzzy evaluation system. Section 4 discusses evaluation results. Section 5 presents the conclusions.

\section{Methodology}

\subsection{Stability evaluation system for high rockfill embankment}

Various factors influence the stability of high rockfill embankment [24]. Selecting appropriate evaluation indexes is of considerable significance to obtain accurate fuzzy evaluation results. With reference to previous findings $[10$, 12, 16], 16 indexes, five classes, two levels (Fig. 1) that significantly affect the stability evaluation of high rockfill embankment according to practical situations were selected in this study and applied to the secondary highway of the National Highway 316 from Xunyang to Ankang. On this basis, a fuzzy evaluation system that can reflect characteristics of high rockfill embankment comprehensively was established.

\subsection{Establishing a fuzzy evaluation model for stability of high rockfill embankment}

\subsubsection{System reliability}

The overall evaluation index system for stability of high rockfill embankment involves multiple influencing factors with complicated relations and typical nonlinear features. Fig. 1 shows the indexes of the established evaluation system. Specifically, the criteria layer comprises five classes of factors, while the factor layer comprises 16 indexes of the criteria layer.

(1) Reliability calculation of the criteria layer

Five classes of factors in the criteria layer are connected in series and the entire layer fails upon failure of any one factor. In this case, the entire evaluation system for stability of high rockfill embankment fails. The reliability of the $i^{\text {th }}$ factor $\left(A_{i}\right)$ in the criteria layer is denoted as $R_{i}$. According to the principle of reliability calculation of a series system, the reliability of the criteria layer $\left(R_{a}\right)$ is shown in Eq. (1) if all factors are assumed to be independent of each other,

$$
R_{a}=\prod_{i=1}^{5} R_{i}
$$

\section{(2) Reliability calculation of the factor layer}

The 16 indexes in the factor layer are in parallel connection. The criteria layer fails if all factors in the 
corresponding factor layer fail. The unreliability of $j^{\text {th }}$ factor covered by the $i^{\text {th }}$ factor $\left(A_{i}\right)$ in the criteria layer is denoted as $R_{j}$. According to the principle of reliability calculation of a parallel system, the reliability of the factor layer $\left(R_{a}\right)$ is shown in Eq. (2) if all factors are assumed to be independent of each other,

$$
R_{a}=1-\prod_{j=1}^{m} R_{j},
$$

where $m$ refers to the number of elements in the $i^{\text {th }}$ factor in the criteria layer and values 5, 3, 4, 2, 2 successively.

The reliability of the criteria layer is equal to that of the entire evaluation system for stability of high rockfill embankment, while the reliability of $A_{i}$ is the reliability of the corresponding factor layer.

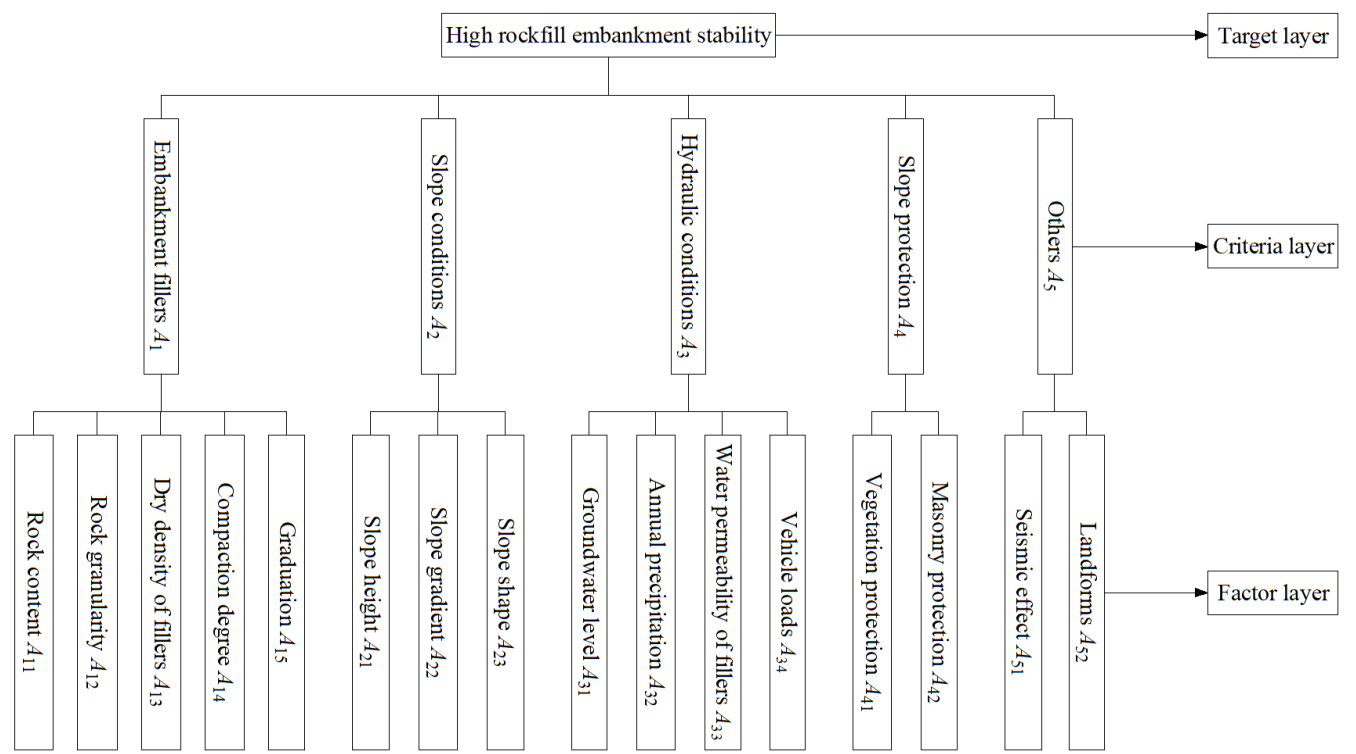

Fig. 1. Indexes in the stability evaluation system of high rockfill embankment

\subsubsection{AHP model}

(1) Construction of a judgment matrix

Weights of evaluation indexes for high rockfill embankment can directly affect comprehensive evaluation results of fuzzy AHP. Therefore, weights of evaluation indexes are determined objectively according to their importance and degrees of impacts on stability. According to the system structure in Fig. 1, pairwise comparisons of importance of factors in each layer relative to targets in the previous layer were carried out using the 1-9 scale (Table 1). Corresponding judgment matrixes were constructed.

Therefore, the judgment matrixes of factors in the criteria layer $A_{k}(k=1,2,3,4,5)$ can be expressed by Eq. (3)

$A_{k}=\left[\begin{array}{cccc}A_{11} & A_{12} & \cdots & A_{1 n} \\ \vdots & A_{22} & \cdots & A_{2 n} \\ \vdots & \vdots & A_{i i} & \vdots \\ A_{n 1} & A_{n 2} & \cdots & A_{n n}\end{array}\right]$

where $A_{i j}=\left\{\begin{array}{ll}1, & i=j \\ 1 / A_{j i}, & i \neq j\end{array}\right.$.

Table 1. Meanings of 1-9 scales

\begin{tabular}{l|l}
\hline Scales & Meanings \\
\hline 1 & $\begin{array}{l}\text { The two factors are equally important } \\
\text { The former factor is slightly more important than the } \\
\text { latter }\end{array}$ \\
5 & $\begin{array}{l}\text { The former factor is evidently more important than the } \\
\text { latter } \\
\text { The former factor is much more important than the } \\
\text { latter }\end{array}$
\end{tabular}

9

$2,4,6,8$

The former factor is extremely more important than the latter

The former factor is more

important than the latter between the above adjacent evels

(2) Determination of index weights

In the criteria layer, weight vectors of factors in the corresponding factor layer can be calculated through a judgment matrix $A_{k}$, which has the following relations with the maximum eigenvalue $\lambda_{\max }$ and eigenvector $\omega_{i}$, as shown in Eq. (4),

$A_{k} \omega=\lambda_{\text {max }} \omega$

$\omega_{i}=\left(\prod_{j=1}^{5} A_{i j}\right)^{1 / n}, i=1,2, \cdots, n$

The eigenvector $\omega_{i}$ (Eq. (5)) is normalized and then used as the weight vector of factors in the factor layer, which are denoted as $\omega_{i}$ if they belong to the corresponding criteria layer and $\omega$ otherwise.

(3) Consistency check

Judgment matrix is constructed after the pairwise comparison of importance of different factors in the system. The consistency check is to verify reasonability of the judgment matrix using the consistency index is shown in Eq. (6), 
$C I=\frac{\lambda_{\max }-n}{n-1}$

The mean random consistency index $(R I)$ can be obtained from the values listed in Table 2.

Table 2. Mean random consistency index

\begin{tabular}{l|l|l|l|l|l|l|l|l|l}
\hline$n$ & 1 & 2 & 3 & 4 & 5 & 6 & 7 & 8 & 9 \\
\hline$R I$ & 0 & 0 & 0.58 & 0.90 & 1.12 & 1.24 & 1.32 & 1.41 & 1.45 \\
\hline
\end{tabular}

When $C R=(C I / R I)<0.1$, the judgment matrix can be considered to meet the consistency requirement, and thus is reasonable and the weight indexes show no contradictions. Otherwise, the judgment matrix is unreasonable and the weight indexes needs adjustments.

\subsubsection{Multilevel fuzzy synthetic evaluation model}

(1) Determining evaluation factor set and evaluation set

An evaluation factor set $U=\left\{u_{1}, u_{2}, u_{3}, \cdots, u_{n}\right\}$ was established to describe the indexes of the evaluation object. $n$ refers to the number of evaluation indexes and is determined by specific index systems. The evaluation set $V=\left\{v_{1}, v_{2}, \cdots, v_{m}\right\}$ is established to describe $m$ evaluation levels of the state where each factor lies in.

(2) Constructing judgment matrixes and determining weights

First, single-factor judgment was performed to factors $u_{i}(i=1,2, \cdots, n)$ in the factor set. Given that the membership degree of factor $u_{i}$ to the evaluation set $v_{j}(j=1,2, \cdots, m)$ is $r_{i j}$, the single-factor judgment set of the $i^{\text {th }}$ factor $\left(u_{i}\right)$ is shown in Eq. (7),

$r_{i}=\left\{r_{i 1}, r_{i 2}, r_{i 3}, \cdots, r_{i m}\right\}$

In this way, the evaluation set consisting of $n$ factors form a total evaluation matrix $R$. Therefore, the fuzzy relations $(R)$ from $U$ to $V$ are determined from each evaluation object, as shown in Eq. (8),

$$
R=\left(r_{i j}\right)_{n \times m}=\left\{\begin{array}{cccc}
r_{11} & r_{12} & \cdots & r_{1 m} \\
\vdots & r_{22} & \cdots & r_{2 m} \\
\vdots & \vdots & r_{i i} & \vdots \\
r_{n 1} & r_{n 1} & \cdots & r_{n m}
\end{array}\right\},
$$

where $i=1,2,3, \cdots, n$ and $j=1,2,3, \cdots, m . \quad r_{i j}$ is the frequency distribution of $u_{i}$ on the $j^{\text {th }}$ comment $v_{j}$. Generally speaking, $r_{i j}$ is normalized to meet $\sum r_{i j}=1$.

Due to the different degrees of influences of evaluation factors, it is necessary to determine their weights. In this study, weights of different evaluation indexes were determined through AHP [25].

(3) Single-level fuzzy synthetic evaluation

The fuzzy synthetic evaluation results of a unit can be gained from $r_{i}$ and weight matrix $B$. In this study, weights of different indexes were determined by the abovementioned AHP, as shown in Eq. (9),

$$
\begin{aligned}
T=R B & =\left\{r_{i 1}, r_{i 2}, r_{i 3}, \cdots, r_{i k}\right\}\left\{\begin{array}{cccc}
b_{11} & b_{12} & \cdots & b_{1 m} \\
\vdots & b_{22} & \cdots & b_{2 m} \\
\vdots & \vdots & b_{i i} & \vdots \\
b_{n 1} & b_{n 1} & \cdots & b_{n m}
\end{array}\right\}, \\
& =\left\{t_{1}, t_{2}, t_{3}, \cdots, t_{k}\right\}
\end{aligned}
$$

where $t_{i}$ refers to the membership degree of a unit to the $i^{\text {th }}$ evaluation level. The synthetic evaluation levels can be determined according to the maximum membership degree principle or the method of weighted mean.

(4) Multilevel fuzzy synthetic evaluation

Different factors can influence stability of complicated systems such as high rockfill embankment. Moreover, different influencing factors have different hierarchical relations. Obtaining reliable evaluation results through single-layer fuzzy synthetic evaluations is difficult, requiring classification and combination of evaluation factors according to specific features. Synthetic evaluation was performed to each class of factors, followed by multilevel synthetic evaluation of evaluation results of different classes.

If a system is divided into $k$ subsystems according to attributes, each subsystem was evaluated using the singlelevel fuzzy synthetic evaluation model. The evaluation results were $k T=\left\{t_{1}, t_{2}, t_{3}, \cdots, t_{k}\right\}$. These $k$ evaluation results $T_{1}, T_{2}, \cdots, T_{m}$ form a new evaluation decision matrix $R^{\prime}$, as shown in Eq. (10),

$R^{\prime}=\left\{\begin{array}{c}T_{1} \\ T_{2} \\ \vdots \\ T_{k}\end{array}\right\}=\left\{\begin{array}{cccc}t_{11} & t_{12} & \cdots & t_{1 m} \\ \vdots & t_{22} & \cdots & t_{2 m} \\ \vdots & \vdots & t_{i i} & \vdots \\ t_{k 1} & t_{k 1} & \cdots & t_{k m}\end{array}\right\}$.

If the weight set of $k$ subsystems is $B^{\prime}$, then the synthetic evaluation result is $E^{\prime}=B^{\prime} \cdot R^{\prime}$. If a system can be divided into more layers of fuzzy synthetic evaluation models, then these layers can each be evaluated according to the abovementioned method, finally obtaining the synthetic evaluation results.

The multilevel fuzzy synthetic evaluation results are recorded as $Q$, which is processed to obtain more explicit final evaluation results. At present, the major processing methods of $Q$ include maximum membership degree and weighted mean.

The maximum membership degree method selects the evaluation result $v_{i}$ in the evaluation set corresponding to the maximum $Q\left(q_{i}\right)$ as the final evaluation result. After this $Q$ processing, $v_{i}$ reflects the maximum possibility but remains incomprehensive. The method of weighted mean is used to calculate the weighted sum of evaluation sets that are quantified by $Q$ and then obtain the final evaluation result according to positions of the weighted values in the quantitative evaluation set. This method comprehensively considers all influencing factors and achieves more accurate final evaluation results [10] than other approaches, and is thus applied in the present study. 


\section{Results analysis and discussion}

According to Table 1 , factor set in the criteria layer was denoted as $U=\left\{A_{1}, A_{2}, A_{3}, A_{4}, A_{5}\right\}$ and the factor set of the factor layer belonging to the factor of criteria layer $A_{i}$ was recorded as $U_{k}=\left\{A_{k 1}, A_{k 2}, \cdots, A_{k n}\right\}$. Moreover, stability of high rockfill embankment was divided into five levels. With reference to [10], the evaluation set of a stability fuzzy evaluation system was set as $V=\left\{v_{1}, v_{2}, v_{3}, v_{4}, v_{5}\right\}$, where $v_{1}, v_{2}, v_{3}, v_{4}, v_{5}$ represents good stability, relatively good stability, moderate stability, relatively poor stability, and poor stability, respectively. Values of these five stability levels were determined as $V=\{100,80,60,40,20\}$.

The possibility of obtaining the $k^{\text {th }}$ evaluation results due to the $j^{\text {th }}$ influencing factor in the factor layer that belongs to $A_{i}$ was recorded as $p_{i j k}, p_{i j k} \in[0,1]$ and $\sum_{k}^{m} p_{i j k}=1$, where $m$ represented the number of factors in the evaluation set, determined as 5 in the present study. The percentage after the weighted sum of $p_{i j k}(k=1,2,3,4,5)$ and the evaluation set $V=\{100,80,60,40,20\}$ was denoted as the safety reliability of the relevant influencing factor.

A fuzzy evaluation of stability of high rockfill embankment was applied to the secondary highway of the National Highway G316 from Xunyang to Ankang. The weights of embankment fillers $A_{1}$ [rock content $\left(A_{11}\right)$, rock granularity $\left(A_{12}\right)$, dry density of fillers $\left(A_{13}\right)$, compaction degree $\left(A_{14}\right)$, and graduation $\left.\left(A_{15}\right)\right]$ in the criteria layer are used taken as example. The corresponding judgment matrix $A_{1}$ was constructed, calculated to obtain its maximum eigenvalue and corresponding eigenvector, and underwent a consistency check. The judgment matrix meets the consistency requirements and the weight distribution is reasonable when $C R<0.1$. The steps taken are as follows.

(1) Constructing the judgment matrix of factor $A_{1}$ :

$$
A_{1}=\left[\begin{array}{ccccc}
1 & 1 / 3 & 3 & 2 & 4 \\
3 & 1 & 2 & 2 & 3 \\
1 / 3 & 1 / 2 & 1 & 1 / 2 & 1 \\
1 / 2 & 1 / 2 & 2 & 1 & 2 \\
1 / 4 & 1 / 3 & 1 & 1 / 2 & 1
\end{array}\right]
$$

(2) Calculate the maximum eigenvalue of $A_{1}$ : $\lambda_{\max }=5.2652$. Then, the eigenvectors of $A_{1}$ are calculated as $(2.352,1.320,0.822,0.922,0.425)$ from Eq. (5) and then normalized to $(0.403,0.226,0.141,0.158,0.072)$, respectively.

(3) Consistency check: $A_{1}$ has five orders and is calculated from Eq. (6) that $C I=0.066$. According to Table 2, $R I=1.12$.

Hence, $\quad C R=(C I / R I)=0.059<0.1$, meeting the consistency requirements. This result indicates that the weight distribution was reasonable.

Similarly, weights of other stability evaluation indexes of high rockfill embankment were determined through twolayer AHP. Table 3 shows the results.

The 16 indexes in the factor layer of the con-structed evaluation system were assessed by consulting multiple experts and engineers engaged in studies of road engineering. Hence, membership degrees of factors in the factor layer to the results in the evaluation set were obtained. Table 4 presents the results.

Table 3. Weights of evaluation indexes

\begin{tabular}{l|l|l|l}
\hline Factors in the criteria layer & Factors in the factor layer & Weights of the criteria layer & Weights of the factor layer \\
\hline \multirow{5}{*}{ Embankment fillers $A_{1}$} & Rock content $\left(A_{11}\right)$ & & 0.266 \\
& Rock granularity $\left(A_{12}\right)$ & & 0.359 \\
& Dry density of fillers $\left(A_{13}\right)$ & 0.385 & 0.107 \\
& Compaction degree $\left(A_{14}\right)$ & & 0.175 \\
& Graduation $\left(A_{15}\right)$ & & 0.093 \\
\hline \multirow{5}{*}{ Slope conditions $A_{2}$} & Slope height $\left(A_{21}\right)$ & & 0.196 \\
& Slope gradient $\left(A_{22}\right)$ & 0.099 & 0.493 \\
& Slope shape $\left(A_{23}\right)$ & & 0.311 \\
\hline \multirow{5}{*}{ Hydraulic conditions $A_{3}$} & Groundwater level $\left(A_{31}\right)$ & & 0.148 \\
& Annual precipitation $\left(A_{32}\right)$ & \multirow{2}{*}{0.263} & 0.362 \\
& Water permeability of fillers $\left(A_{33}\right)$ & & 0.327 \\
& Vehicle loads $\left(A_{34}\right)$ & 0.163 \\
\hline \multirow{2}{*}{ Others $A_{5}$} & Vegetation protection $\left(A_{41}\right)$ & \multirow{2}{*}{0.192} & 0.4 \\
& Masonry protection $\left(A_{42}\right)$ & & 0.6 \\
\hline
\end{tabular}


Table 4. Membership degrees of factors in the factor layer

\begin{tabular}{|c|c|c|c|c|c|c|}
\hline Criteria layer & Factor layer & Good stability & $\begin{array}{l}\begin{array}{l}\text { Relatively good } \\
\text { stability }\end{array} \\
\end{array}$ & $\begin{array}{l}\text { Moderate } \\
\text { stability }\end{array}$ & $\begin{array}{ll}\begin{array}{l}\text { Relatively poor } \\
\text { stability }\end{array} \\
\end{array}$ & Poor stability \\
\hline \multirow{5}{*}{$A_{1}$} & $A_{11}$ & 0.2 & 0.4 & 0.3 & 0.1 & 0 \\
\hline & $A_{12}$ & 0.1 & 0.4 & 0.4 & 0.1 & 0 \\
\hline & $A_{13}$ & 0.2 & 0.5 & 0.2 & 0.1 & 0 \\
\hline & $A_{14}$ & 0.2 & 0.3 & 0.5 & 0 & 0 \\
\hline & $A_{15}$ & 0.2 & 0.3 & 0.4 & 0.1 & 0 \\
\hline \multirow{3}{*}{$A_{2}$} & $A_{21}$ & 0.1 & 0.4 & 0.4 & 0.2 & 0 \\
\hline & $A_{22}$ & 0.1 & 0.3 & 0.5 & 0.1 & 0 \\
\hline & $A_{23}$ & 0.2 & 0.5 & 0.3 & 0 & 0 \\
\hline \multirow{4}{*}{$A_{3}$} & $A_{31}$ & 0 & 0 & 0.4 & 0.5 & 0.1 \\
\hline & $A_{32}$ & 0 & 0.2 & 0.5 & 0.2 & 0.1 \\
\hline & $A_{33}$ & 0.2 & 0.3 & 0.5 & 0 & 0 \\
\hline & $A_{34}$ & 0 & 0.2 & 0.6 & 0.2 & 0 \\
\hline \multirow{2}{*}{$A_{4}$} & $A_{41}$ & 0.6 & 0.3 & 0.1 & 0 & 0 \\
\hline & $A_{42}$ & 0.7 & 0.2 & 0.1 & 0 & 0 \\
\hline \multirow{2}{*}{$A_{5}$} & $A_{51}$ & 0 & 0.5 & 0.3 & 0.1 & 0.1 \\
\hline & $A_{52}$ & 0.2 & 0.3 & 0.5 & 0 & 0 \\
\hline
\end{tabular}

Weights and membership degrees of different factors were obtained from Tables 3 and 4. Synthetic evaluation results of factors in the criteria layer could be determined through the matrix operation $E_{i}=\omega_{i} P_{i},(i=1,2,3,4,5)$ (where $\omega_{i}$ is weight and $P_{i}$ is membership degree). These synthetic evaluation results formed the fuzzy evaluation matrix of the criteria layer.

$$
E=\left[\begin{array}{l}
E_{1} \\
E_{2} \\
E_{3} \\
E_{4} \\
E_{5}
\end{array}\right]=\left[\begin{array}{ccccc}
0.1614 & 0.3839 & 0.3695 & 0.0825 & 0 \\
0.1311 & 0.3818 & 0.4182 & 0.0885 & 0 \\
0.0654 & 0.2031 & 0.5015 & 0.1790 & 0.0510 \\
0.6800 & 0.2400 & 0.1000 & 0 & 0 \\
0.1000 & 0.4000 & 0.4000 & 0.0500 & 0.0500
\end{array}\right]
$$

The stability evaluation result of high rockfill embankment was $Q$. The comprehensive score of the stability evaluation of high rockfill embankment was $W$.

$$
\begin{aligned}
& Q=\omega E=\left[\begin{array}{llllll}
0.385 & 0.099 & 0.263 & 0.192 & 0.061
\end{array}\right] \\
& {\left[\begin{array}{ccccc}
0.1614 & 0.3839 & 0.3695 & 0.0825 & 0 \\
0.1311 & 0.3818 & 0.4182 & 0.0885 & 0 \\
0.0654 & 0.2031 & 0.5015 & 0.1790 & 0.0510 \\
0.6800 & 0.2400 & 0.1000 & 0 & 0 \\
0.1000 & 0.4000 & 0.4000 & 0.0500 & 0.0500
\end{array}\right]} \\
& \quad=\left[\begin{array}{lllll}
0.2290 & 0.3095 & 0.3592 & 0.0907 & 0.0165
\end{array}\right]
\end{aligned}
$$$$
W=Q V^{T}
$$$$
=\left[\begin{array}{lllll}
0.2290 & 0.3095 & 0.3592 & 0.0907 & 0.0165
\end{array}\right]
$$$$
\left[\begin{array}{lllll}
100 & 80 & 60 & 40 & 20
\end{array}\right]^{T}=73.1619
$$

Based on the principle in Section 3.1, reliability of the evaluation system was calculated as $F=P V^{T} / 100$. Table 5

\begin{tabular}{|c|c|c|c|c|}
\hline Criteria layer & Factor layer & $\begin{array}{l}\text { Reliability of criteria } \\
\text { layer }\end{array}$ & Reliability of factor layer & $\begin{array}{lrl}\begin{array}{l}\text { Reliability of } \\
\text { evaluation system }\end{array} & \text { the } \\
\end{array}$ \\
\hline \multirow{5}{*}{$A_{1}$} & $A_{11}$ & \multirow{5}{*}{0.9986} & 0.74 & \multirow{13}{*}{0.8671} \\
\hline & $A_{12}$ & & 0.70 & \\
\hline & $A_{13}$ & & 0.76 & \\
\hline & $A_{14}$ & & 0.74 & \\
\hline & $A_{15}$ & & 0.72 & \\
\hline \multirow{3}{*}{$A_{2}$} & $A_{21}$ & \multirow{3}{*}{0.9817} & 0.74 & \\
\hline & $A_{22}$ & & 0.68 & \\
\hline & $A_{23}$ & & 0.78 & \\
\hline \multirow{4}{*}{$A_{3}$} & $A_{31}$ & \multirow{4}{*}{0.9753} & 0.46 & \\
\hline & $A_{32}$ & & 0.56 & \\
\hline & $A_{33}$ & & 0.74 & \\
\hline & $A_{34}$ & & 0.60 & \\
\hline$A_{4}$ & $A_{41}$ & 0.9920 & 0.90 & \\
\hline
\end{tabular}
shows the results.

Table 5. Calculated results of reliability of the evaluation system 


\begin{tabular}{l|l|l|l|l}
\hline & $A_{42}$ & & 0.92 & \\
\cline { 1 - 2 }$A_{5}$ & $A_{51}$ & 0.9142 & 0.67 & \\
& $A_{52}$ & 0.74 & \\
\hline
\end{tabular}

\section{Conclusions}

In this study, a multilevel fuzzy synthetic evaluation model for stability of high rockfill embankment is constructed on the basis of fuzzy mathematics theory with considerations for practical engineering conditions. This model realizes fast and effective stability evaluation of high rockfill embankment. Several major conclusions can be drawn:

(1) With considerations for the complexity of high rockfill embankment, a relatively overall multilayer fuzzy synthetic evaluation index system for the stability of high rockfill embankment is constructed by combining relevant research conclusions and practical engineering conditions.

(2) The main influencing factors of stability of high rockfill embankment and their correlations are considered. Moreover, a multilevel fuzzy synthetic evaluation model for stability of high rockfill embankment is constructed by combining reliability theory, fuzzy mathematics theory, and AHP. With this model, a systematic evaluation of stability of high rockfill embankment is realized. Moreover, reliabilities of different factors and reliability of the whole evaluation system are determined on the basis of reliability theory.
(3) The constructed evaluation model is applied to the high rockfill embankment in the secondary highway of the National Highway 316 from Xunyang to Ankang in the Shaanxi Province, China. The reliability is 0.8671 and the final score of the evaluation system is 73.1619. The embankment is at a relatively stable state. Fuzzy evaluation results are consistent with practical engineering conditions, thus verifying reasonability of the model. Therefore, the proposed fuzzy evaluation model is reasonable and feasible to evaluate stability of high rockfill embankment.

The proposed multilevel fuzzy synthetic evaluation index system can provide beneficial references for fast and effective evaluation of high rockfill embankment stability. The key in application of this model lies in the construction of an accurate evaluation index system. However, the proposed model needs further improvements to enable applications to varied engineering environments in different regions.

This is an Open Access article distributed under the terms of the Creative Commons Attribution License.

\section{References}

1. Rabie, M., "Performance of hybrid MSE/Soil Nail walls using numerical analysis and limit equilibrium approaches". Housing and Building National Research Center Journal, 12(1), 2016, pp. 63-70.

2. Agam, M. W., Hashim, M. H. M., Murad, M. I., Zabidi, H., "Slope sensitivity analysis using Spencer's Method in comparison with general limit equilibrium method". Procedia Chemistry, 19, 2016, pp. 651-658.

3. Zhou, X. P., Zhao, Y., Qian, Q. H., "A novel meshless numerical method for modeling progressive failure processes of slopes". Engineering Geology, 192, 2015, pp. 139-153.

4. Yang, Y. T., Sun, G. H., Zheng, H., "Stability analysis of soil-rockmixture slopes using the numerical manifold method". Engineering Analysis with Boundary Elements, 109, 2019, pp. 153-160.

5. Napoli, L. M., Barbero, M., Ravera E., Scavia, C., "A stochastic approach to slope stability analysis in bimrocks". International Journal of Rock Mechanics and Mining Sciences, 101, 2018, pp. 41-49.

6. Li, A. J., Khoo, S., Lyamin, A. V., Wang, Y., "Rock slope stability analyses using extreme learning neural network and terminal steepest descent algorithm". Automation in Construction, 65, 2016, pp. $42-50$.

7. Hernandez-Lopez, A., Vazquez-Lopez, J., Lopez-Juarez, I., BaezaSerrato, R., Gonzalez-Calderon, J., "An ensemble model for statistical monitoring of patterns in bivariate processes based on multiple artificial neuronal networks". DYNA, 95(2), 2020, pp. 181186.

8. Wang, N., Zhang, J. M., Xu, K., Hu, J. Z., "Robust control of multi degree of freedom robot based on disturbance observer of neural network". Journal of Engineering Science and Technology Review, 13, 2020, pp. 143-151.

9. Das, U., Biswas, P. K., "Closed loop speed control of BLDC motor drive by using classical controllers with genetic algorithm". Journal of Power Technologies, 100(2), 2020, pp. 161-170.

10. Liu, H., Niu, F. J., Niu, Y. H., Xu, J., "Comprehensive evaluation on stability of roadbed of high-speed railway in seasonal frozen regions based on fuzzy mathematic". Journal of Xian University of Architecture and Technology (Natural Science Edition), 46(3), 2014, pp. 367-375.
11. Marandi, S. M., Anvar, M., Bahrami, M., "Uncertainty analysis of safety factor of embankment built on stone column improved soft soil using fuzzy logic $\alpha$-cut technique". Computers and Geotechnics, 75, 2016, pp. 135-144.

12. Huang, C. F., Li, Q., Wu, S. C., Liu, Y., "Subgrade stability evaluation in permafrost regions based on unascertained measurement model". Geotechnical and Geological Engineering, 37. 2019, pp. 707-719.

13. Ruan, G. F., Zhang, J. M., Mu, Y. H., Zhang, H., Chai, M. T., "Evaluation of the embankment thermal stability over permafrost based on entropy-weight and matter-element extension model". Journal of Glaciology and Geocryology, 36(1), 2014, pp. 123-129.

14. Park, H. J., Um, J.G., Woo, I., Kim, J. W., "Application of fuzzy set theory to evaluate the probability of failure in rock slopes". Engineering Geology, 125, 2012, pp. 92-101.

15. Azarafza, M., Akgün, H., Feizi-Derakhshi, M. R., Azarafza, M., Rahnamarad, J., Derakhshani, R., "Discontinuous rock slope stability analysis under blocky structural sliding by fuzzy key-block analysis method". Heliyon, 6(5), 2020, pp. e03907.

16. Su, H. Z., Li, J.Y., Cao, J.P., Wen, Z. P., "Macro-comprehensive evaluation method of high rock slope stability in hydropower projects". Stochastic Environmental Research and Risk Assessment, 28(2), 2014, pp. 213-224.

17. Daftaribeshelia, A., Ataeib, M., Sereshkib, F., "Assessment of rock slope stability using the Fuzzy Slope Mass Rating (FSMR) system". Applied Soft Computing, 11(8), 2011, pp. 4465-4473.

18. Ye, S.H., Fang, G. W., Ma, X. R., "Reliability analysis of grillage flexible slope supporting structure with anchors considering fuzzy transitional interval and fuzzy randomness of soil parameters". Arabian Journal for Science and Engineering, 44(10), 2019, pp. 8849-8857.

19. Zhu, H. W., Yao, L. K., Luo, Y., "Seismic stability evaluation of embankment slope based on catastrophe theory". Journal of Modern Transportation, 21(2), 2013, pp. 111-116.

20. Sari, P. A., Suhatril, M., Osman, N., Mu'azu, M. A., Katebi, J., Abavisani, A., Ghaffari, N., Chahnasir, E. S., Wakil, Khorami, K., M., Petkovic, D., "Developing a hybrid adoptive neuro-fuzzy inference system in predicting safety of factors of slopes subjected to surface eco-protection techniques". Engineering with Computers, 36(6), 2020, pp. 1347-1354. 
21. Gao, W., Wang, X., Dai, S., Chen, D. L., "Study on stability of high embankment slope based on black hole algorithm". Environmental Earth Sciences, 75(20), 2016, pp. 1381

22. Moghadami, M., Mortazavi, A., "Development of a risk-based methodology for rock slope analysis". International Journal of Civil Engineering 16, 2018, pp. 1317-1328.

23. Ruan, H., Y. Zhang, H., Zhu, Z. Q., Wang, J., “An improved fuzzy method for evaluating stability of highway slopes". Rock and Soil Mechanics, 36(11), 2015, pp. 3337-3344.
24. Zhang, Y. Q., Jing, H. J., Dai, J., Li, S. F, Zhang, Z., "Stability of high rockfill embankment based on orthogonal test and numerical simulation". Tehnicki Vjesnik-Technical Gazette, 27(1), 2020, pp. 191-199.

25. Bonyadi, N., Asghari, H., Kiaei, M., "Identification and prioritization of employee satisfaction strategies in Tehran Regional Water Company using analytic hierarchy process (AHP)". Tehnički glasnik, 14 (3), 2020, pp. 251-256. 